\title{
Analysis and Characterization of Embrittlement in Archaeological Silver and Iron
}

\author{
R.J.H. Wanhill,*
}

* Aerospace Vehicles Division, National Aerospace Laboratory NLR, P.O. Box 153, 8300

AD Emmeloord, the Netherlands

Embrittlement of originally ductile archaeological metals is, or can be, a complex phenomenon. The analysis and characterization of embrittlement requires sophisticated techniques that were unavailable a generation ago and are as yet underexploited by the archaeological community. It is important to understand the details and mechanisms of embrittlement in order to select the best remedial measures for restoration and conservation. This paper presents a survey of the techniques used to investigate the embrittlement of several archaeological silver objects and an iron pile-shoe from a Roman bridge.

Several embrittled silver objects with widely varying provenance have been investigated by the NLR since 1994. These are an Egyptian Vase, the Gundestrup Cauldron and a Byzantine Paten. Another object, a Roman Kantharos, is currently being examined. The experience gained from these investigations has enabled the basic mechanisms of embrittlement to be determined and specification of the appropriate diagnostic techniques [1-3]. The diagnostic techniques include visual inspection, X-ray radiography, optical metallography, scanning electron microscopy using both secondary electron and backscattered electron imaging, electron backscatter diffraction imaging, energy or wavelength dispersive analysis of X-rays, and microhardness testing. These techniques are discussed in relation to their purposes and limitations.

A Roman pile-shoe recovered from the Maas riverbed and made from four iron bars had three broken bars. One break was recent owing to impact fracture when falling onto a concrete floor in a storage area. The fracture was extremely brittle and samples from the same location could be fragmented by hammer blows. The NLR collaborated with three other institutes in analysing this type of fracture [4-5]. The diagnostic techniques were optical and scanning electron microscope fractography and metallography, bulk and local chemical analyses, and $\mathrm{X}$-ray photoelectron spectroscopy of a freshly prepared fracture surface. As before, these techniques are discussed in relation to their purposes and limitations.

\section{References}

[1] R.J.H. Wanhill, J. Failure Analysis and Prevention, 5 (No.1) (2005) 41.

[2] R.J.H. Wanhill, NLR Technical Publication NLR-TP-2002-224, National Aerospace Laboratory NLR, Amsterdam, the Netherlands, 2002.

[3] R.J.H. Wanhill, A lecture course on metallurgy, embrittlement and conservation of ancient silver, National Aerospace Laboratory NLR, Amsterdam, the Netherlands, 2008.

[4] R.J.H.Wanhill, P.A. Seinen, R.A., Rijkenberg and H.J.M. Meijers, Historical Metallurgy, 41 (Part 1) (2007) 32.

5. R.J.H. Wanhill, P.A. Seinen, R.A. Rijkenberg and H.J.M. Meijers, NLR Technical Publication NLR-TP-2007-045, National Aerospace Laboratory NLR, Amsterdam, the Netherlands, 2007. 